\title{
Averrhoa carambola Linn: Is It Really a Toxic Fruit?
}

\author{
Lydia Ferrara $^{1 *}$ \\ 'Department of Pharmacy, University of Naples Federico II, Naples, Italy
}

Corresponding Author: Lydia Ferrara, Department of Pharmacy, University of Naples Federico II, Via Domenico Montesano 49, 80131 Naples, Italy. Tel: +39-3331931172, Email: lyferrar@unina.it

Received January 20, 2018; Accepted February 11, 2018; Online Published March 20, 2018

\begin{abstract}
Averrhoa carambola, or star fruit, is a tropical fruit found throughout Southeast Asia and is usually consumed fresh or as fruit juice. The fruit is a very good source of natural antioxidants, phenolic compounds such as gallic acid in gallotannin form, catechins, and epicatechins. Various medicinal uses for carambola are found in folk medicine. In India, the ripe fruit is administered to halt hemorrhaging, and the dried fruit or the juice may be taken to counteract fevers; star fruit jam is said to allay biliousness and diarrhea and to relieve a hangover from excessive indulgence in alcohol. In Brazil, carambola is recommended as a diuretic and for the treatment of eczema. Because of the high concentrations of oxalic acid present in carambola, the excessive consumption of its fruit by dialysis patients can cause neurotoxicity and impair cognitive abilities and, if there is no immediate relief, even death. In addition to oxalic acid which is responsible for nephrotoxic phenomena in subjects with impaired renal function, caramboxin has recently been identified as a substance that acts on the central nervous system causing symptoms such as sobbing, confusion, and in more serious conditions, convulsions and death.

Keywords: Nutritional Sciences, Oxalic Acid, Toxicity, Caramboxin

Citation: Ferrara L. Averrhoa carambola Linn: is it really a toxic fruit? Int J Med Rev. 2018;5(1):2-5. doi:10.29252/IJMR-050102.
\end{abstract}

\section{Introduction}

Averrhoa carambola belongs to the family of Oxalidaceae. It originated in Sri Lanka, India and the Moluccas and found throughout Southeast Asia. Moreover, it is cultivated in Brazil, Ghana, Guyana, and French Polynesia. A. carambola is a small tree with a short trunk and a branched round crown. Its leaves are arranged spirally, measure $15-20 \mathrm{~cm}$ in length, and alternate from light green above to whitish and hairy in the lower part. They are light-sensitive and tend to bend all together during the night. Its flowers are collected in small pedunculated bunches, like lilacs; the fruits are showy in shape, measure 7-15 cm long and $9 \mathrm{~cm}$ broad, and have a thin skin and orange-yellow flesh when ripe. When they are sliced in cross sections, they show a characteristic star shape. The fruit has a pronounced odor of oxalic acid and different flavors from very sour to sweet. ${ }^{1}$

The concentrations of the principle nutrients vary between the unripe fruit and the ripe one, both the sour and sweet variety, and the concentrations of organic acids. Two varieties are known. The first, Averrhoa bilimbi, is native to Cuba. It has small, green, acidic, and sour fruit not suitable for food. However, it can be used as an aliment for bees, an anti-rust agent for cleaning metals, a stain for dyes, and a stain remover for cloth. Their fruity smell is the basis of many perfumes and colognes. The second variety, A. carambola, with its large, sweet, golden-yellow fruit is widely used in Asian food, and its juice is an excellent thirst-quencher in the summer. Its chemical composition has antioxidant and antimicrobial properties: it acts above all against Escherichia coli, Klebsiella, Staphylococcus aureus, and Pseudomonas aeruginosa. The fruit is also used as a remedy against sunburn. ${ }^{2}$

\section{Chemical Composition}

Carambola is a low-calorie fruit with only $34 \mathrm{cal} / 100 \mathrm{~g}$. The chemical composition is protein $0.38 \mathrm{~g}$; lipids $0.08 \mathrm{~g}$; carbohydrates $9.38 \mathrm{~g}$; fiber $0.80-0.90 \mathrm{~g}$; water $80 \%$; vitamins $\mathrm{A}, \mathrm{E}$, group $\mathrm{B}$, and $\mathrm{C}$; $\mathrm{Ca}, \mathrm{Fe}, \mathrm{Mn}, \mathrm{Mg}, \mathrm{P}, \mathrm{Na}, \mathrm{Zn}$, and a high concentration of $\mathrm{K}$; flavonoids such as quercetin, lutein, and zeaxanthin; and $\alpha$ and $\beta$ carotene. Among the organic acids, oxalic acid is present in a higher concentration: up to $7 \mathrm{mg} / \mathrm{g}$ in sour varieties and $0.4-0.8 \mathrm{mg} / \mathrm{g}$ for sweet varieties. The fruit also contains citric, malic, fumaric, tartaric, succinic and $\alpha$-chetoglutaric acids. The amino acid composition was determined by gas chromatography according to the Chaves das Neves method $^{3}$ (Figure 1), and the concentrations of the identified amino acids are shown in Table $1 .^{4}$

There are also high concentrations of insoluble fibers, mucilage terpenes, enzymes, and tannins in the fruit. Recently, caramboxin was identified as a substance characterized by a structure similar to phenylalanine, which is considered responsible for the toxicity of the fruit on the central nervous system.

\section{Carambola as Food}

Ripe carambolas are eaten as fresh fruit, cut and served as salads, or used as a garnish to avocado or fish dishes. Asian

Copyright $\odot 2018$ The Author(s). This is an open-access article distributed under the terms of the Creative Commons Attribution License (http:// creativecommons.org/licenses/by/4.0), which permits unrestricted use, distribution, and reproduction in any medium, provided the original work is properly cited. 


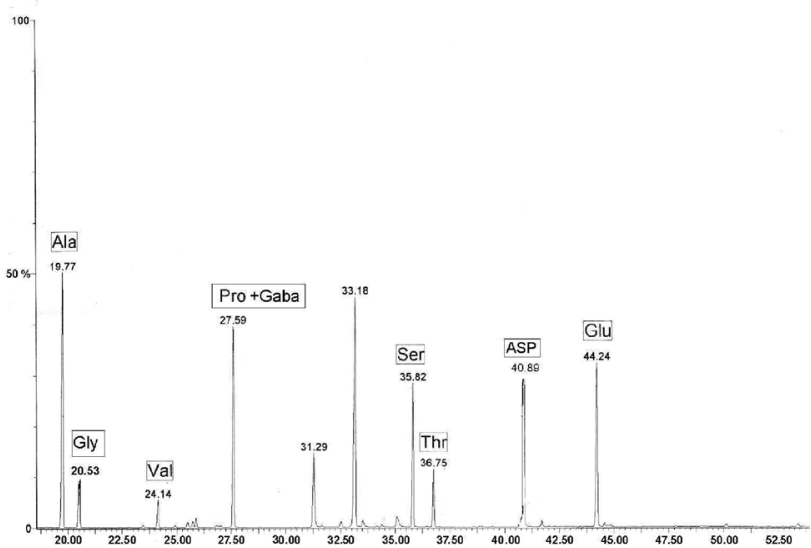

Figure 1. Gas Chromatogram of Amino Acids.

Table 1. Amino Acids Identification

\begin{tabular}{lc}
\hline Amino acids & Mcg/g \\
\hline Asparagine & 108.34 \\
\hline Threonine & 94.10 \\
Serine & 407.75 \\
\hline Glutamic acid & 354.58 \\
Proline & 26.48 \\
Glycine & 15.01 \\
Alanine & 481.08 \\
Valine & 19.92 \\
\hline G-amino-butyric acid & 79.40 \\
\hline
\end{tabular}

populations cook with these fruits in different ways, from jams to sauces and sausages to cakes. Malaysians, for example, usually prepare a sauce by boiling the fruit with sugar, cloves, and apples; the Chinese cook the fruit with fish; Thais boil the unripe fruit with shrimp.

The fruit that are not completely ripe are marinated, salted, and put in vinegar. After being left to macerate in honey for one night, they are cooked for a short time, transformed into jams, and put into sterilized jars. ${ }^{5}$ In many cities in China and Taiwan, carambolas are cut into strips and boxed for export. ${ }^{6}$ Even the juice, with its sour taste, is used as a refreshing drink or as a condiment on fish. An excellent sorbet is prepared from the juice after sugar, lemon juice, and gelatin are added and the mixture is left for some hours at low temperatures.

It is also possible to obtain an alcoholic beverage from carambola by allowing ripe and fresh carambola to ferment with the addition of yeasts such as Saccharomyces cerevisiae, which transforms the sugars naturally present in the fruit into alcohol and $\mathrm{CO}_{2}$. After 5 days of fermentation at $25^{\circ} \mathrm{C}$, the process reaches the final stage with the production of a fruit wine with an alcohol content of over $11^{\circ} / \mathrm{L} .^{7,8}$

Even the flowers and leaves of this plant are used in salads, to which they confer a slightly sour and delicate taste. Because of its original shape, it is used as a garnish on pastry and in the preparation of drinks with an exotic taste, while the pulp can also be transformed into candied fruit.

\section{Pharmacological Activity}

In traditional Indian medicine, the ripe fruit is used to curb bleeding, while the dried fruit or juice is used to treat fevers. A fruit sauce is a soothing treatment for liver crises, especially after excessive ingestion of alcoholic beverages; an ointment made from the fruit is also used to relieve eye pain. In traditional Chinese medicine, carambola juice is indicated to calm thirst, induce salivary secretion, and as an anti-fever agent. A decoction of fruit and leaves also serves to combat vomiting. The crushed leaves tied to the temples offer relief from migraines. A poultice of its leaves and buds is applied on skin rashes in cases of varicella. The leaves are used in traditional Brazilian medicine for the treatment of hypertension ${ }^{9,10}$ and in the prevention of diabetes. ${ }^{11}$ Its roots pounded with sugar are considered an antidote of poisoning; a decoction of crushed seeds has galactogenic and emmenagogue action, and the seed flour has sedative action in cases of asthma and colic. The insoluble fibers obtained as waste from the production of carambola juice have the ability to retain large amounts of water, more than cellulose, helping the regular movement of the intestine. Moreover, they have the ability to lower blood glucose by slowing the absorption of carbohydrates in the body. ${ }^{12,13}$

Carambola fruit is widespread and widely used by populations in Asia and South America both as a fruit and as a juice, especially for its thirst-quenching effects. Phytochemical and pharmacological studies have highlighted the presence of many beneficial substances for the body. Extracts of the star-fruit plant leaves, fruit, and roots contain saponins, flavonoids, alkaloids, and tannins which are known to confer antioxidant and specific healing properties. The flavonoids and the mucilage present in the leaves have antiinflammatory effects on both the mucous membranes of the internal organs and the skin, reducing eczema and acne, with consequent antibacterial action. ${ }^{14,15}$

Waste products from the extracted juice contain high concentrations of fibers consisting of pectic and hemicelluloses, substances with water retention capacity, swelling properties, and cation exchange capacity superior to those of cellulose. Studies have shown that, because of their ability to absorb glucose and reduce amylase activity, such fibers could help control postprandial blood sugar. ${ }^{11,6}$

In the carambola fruit, some enzymes were found that, in addition to being involved in the ripening process of the fruit, exert cleavage action on antioxidant substances such as catechins, epicatechin, proanthocyanidins, and saponins present in the fruit and have well-known hepatoprotective properties. ${ }^{17,18}$ These enzymes are also responsible for the aroma of the fruit as it results from the cleavage activity of an enzymatic fraction on carotenoids isolated from the fruit peel of A. carambola. ${ }^{19}$ The enzymatic activity detected spectrophotometrically showed the degradation of $\beta$-carotene to $\beta$-ionone with the release of the characteristic aroma of the fruit.

Some phenomena of nephrotoxicity related to the high concentration of oxalic acid present in it appeared following the intake of high quantities of the fruit and caused alarm. 
Numerous research results, even contradictory ones, are present in the literature regarding the toxicity of the fruit. The studies concern the damage to which nephropathic patients can be exposed in case of consumption of this fruit; nausea, vomiting, and abdominal pain followed by renal blockage are symptoms caused by the ingestion of large amounts of carambola juice. ${ }^{20,21}$

Undergoing hemodialysis and having pathological examinations show changes typical of nephropathy for oxalates, patients resumed normal renal function without other treatments after 4 weeks. In other cases, in addition to the acute renal failure caused by not only the obstructive effect of calcium oxalate crystals, but also the apoptosis of renal epithelial cells, some authors have reported the presence of neurotoxic symptoms (intractable hiccups, vomiting, insomnia, back pain, mental confusion, epileptic seizures) that were fatal for patients. ${ }^{22,23}$

The neurotoxic activity shown following ingestion of star fruit dates back to 1980, when the fruit extract injected into the peritoneal cavity of mice at a dose of $8 \mathrm{~g} / \mathrm{kg}$ caused convulsions ${ }^{9}$ attributed to oxalic acid. ${ }^{24}$ New studies have attributed the neurotoxic effect on the central nervous system to caramboxin, a substance that acts by inhibiting the GABAergic system with the onset of confusion, hiccups, convulsions, and death. The severity of symptoms was dose dependent, having occurred in patients with kidney disease who were unable to eliminate toxic substances and had consumed up to eight carambola fruits or drunk more than $2 \mathrm{~L}$ of juice. The lethal dose of oxalate that can cause acute oxalate nephropathy for humans varies from 2 to $30 \mathrm{~g}$, and the concentration of soluble oxalate in star fruit varies from 80 to $730 \mathrm{mg} / 100 \mathrm{~mL}$. Furthermore, research has shown that attributing toxicity to the fruits of carambola is unjustified; when only one fruit is consumed by individuals who do not suffer from kidney disease, both oxalic acid and caramboxin are eliminated without causing any harmful effects. ${ }^{25}$

\section{Conclusions}

The presence of new tropical fruits on the market, even if only at certain times of the year, requires a thorough study on the nutritional value, edibility, and genuineness of the product so as to positively influence the consumer. No studies to date have highlighted the importance of the food use of carambola, despite it being a fruit with a low caloric content and a negligible lipid concentration. Studies on carambola mainly relate to the toxicity of oxalic acid in subjects suffering from kidney disease or in dialysis. Subjects with efficient kidney function showed no toxicity after taking a regular dose of the fruit; only in rare cases was a passing hiccup reported.

Commercial carambola juices are usually prepared by placing the fruit in brine. The dilution process considerably reduces the oxalate content, while the pure juice obtained from the fresh fruit and used in traditional medicine is slightly diluted after the brine and contains high amounts of oxalate. An empty stomach and a state of dehydration could pose an additional risk for kidney damage. To avoid toxicity, neither pure carambola juice nor the undiluted juice should be consumed in large quantities, especially on an empty stomach or in a state of kidney failure.

Currently, scientists are focusing their research on methods to lower the concentration of toxic substances in the fruit, such as the precipitation of oxalic acid from the juice ${ }^{26}$ or the removal of caramboxin. Genetic studies will also be conducted to determine methods for reducing the biosynthesis of these such substances specifically to improve the nutritional qualities of the fruit.

\section{Conflict of Interest Disclosures}

The author declares that she has no conflicts of interest.

\section{References}

1. Dasgupta P, Chakraborty P, Bala NN. Averrhoa carambola: an updated review. Int J Pharma Res Rev. 2013;2(7):54-63.

2. Shui G, Leong LP. Analysis of polyphenolic antioxidants in star fruit using liquid chromatography and mass spectrometry. J Chromatogr A.2004;1022(1-2):67-75.doi:10.1016/j.chroma.2003.09.055.

3. Chaves Das Neves HJ, Vasconcelos AM. Capillary gas chromatography of amino acids, including asparagine and glutamine: sensitive gas chromatographic-mass spectrometric and selected ion monitoring gas chromatographic-mass spectrometric detection of the $\mathrm{N}, \mathrm{O}(\mathrm{S})$-tert.-butyldimethylsilyl derivatives. J Chromatogr. 1987;392:249-258. doi:10.1016/S00219673(01)94270-0

4. Ferrara L Proprietà funzionali di Averrhoa carambola L. Ingr Ali. 2009;3:16-19.

5. Prati P, Nogueira JN, Dias CTDS. Avaliação de carambola (Averrhoa carambola L.) dos tipos doce e ácido para o processamento de fruta em calda. Bol Cent Pesqui Process Aliment. 2002;20(2):221246. doi:10.5380/cep.v20i2.1249.

6. Roopa N, Chauhan OP, Raju PS, Das Gupta DK, Singh RK, Bawa AS. Process optimization for osmo-dehydrated carambola (Averrhoa carambola L) slices and its storage studies. J Food Sci Technol. 2014;51(10):2472-2480. doi:10.1007/s13197-0120756-2.

7. Napahde S, Durve A, Bharati D, Chandra N. Wine production from Carambola (Averrhoa carambola) juice using Saccharomyces cerevisiae. Asian J Exp Biol Sci. 2010;1:20-23.

8. Valim FP, Aguiar-Oliveira E, Kamimura ES, Alves VD, Maldonado RR. Production of star fruit alcoholic fermented beverage. Indian J Microbiol. 2016;56(4):476-481. doi:10.1007/s12088-016-06019.

9. Muir CK, Lam CK. Depressant action of Averrhoa carambola. Med J Malaysia. 1980;34(3):279-280

10. Soncini R, Santiago MB, Orlandi L, et al. Hypotensive effect of aqueous extract of Averrhoa carambola L. (Oxalidaceae) in rats: an in vivo and in vitro approach. J Ethnopharmacol. 2011;133(2):353357. doi:10.1016/j.jep.2010.10.001.

11. Ferreira EB, Fernandez LC, Galende SB, Cortez DAG, Bazotte RB. Hypoglycemic effect of the hydroalcoholic extract of leaves of Averrhoa carambola L. (Oxalidaceae). Rev Bras Farmacogn. 2008;18(3):339-343. doi:10.1590/S0102-695X2008000300005.

12. Mahattanatawee K, Manthey JA, Luzio G, Talcott ST, Goodner K, Baldwin EA. Total antioxidant activity and fiber content of select Florida-grown tropical fruits. J Agric Food Chem. 2006;54(19):7355-7363. doi:10.1021/jf060566s.

13. Shui G, Leong LP. Residue from star fruit as valuable source for functional food ingredients and antioxidant nutraceuticals. Food Chem. 2006;97(2):277-284. doi:10.1016/j. foodchem.2005.03.048.

14. Goncalves ST, Baroni S, Bersani-Amado FA, et al. Preliminary studies on gastric anti-ulcerogenic effects of Averrhoa carambola in Rats. Acta Farm Bonaerense. 2006;25(2):245-247. 
15. Cabrini DA, Moresco HH, Imazu P, et al. Analysis of the potential topical anti-inflammatory activity of Averrhoa carambola L. in Mice. Evid Based Complement Alternat Med. 2011;2011:908059. doi:10.1093/ecam/neq026.

16. Chau $\mathrm{CF}$, Chen $\mathrm{CH}$, Lin $\mathrm{CY}$. Insoluble fiber rich fractions derived from Averrhoa carambola: hypoglycemic effects determined by in vitro methods. LWT Food Sci Technol. 2004;37(3):331-335. doi:10.1016/j.Iwt.2003.10.001.

17. Singh R, Sharma J, Goyal PK. Prophylactic role of Averrhoa carambola (star fruit) extract against chemically induced hepatocellular carcinoma in Swiss albino mice. Adv Pharmacol Sci. 2014;2014: 158936. doi:10.1155/2014/158936.

18. Tadros SH, Sleem AA. Pharmacognostical and biological study of the stem and leaf of Avehrroa carambola L. Bull Fac Pharm. 2004; 42:225-246.

19. Fleischmann P, Watanabe N, Winterhalter P. Enzymatic carotenoid cleavage in star fruit (Averrhoa carambola). Phytochemistry. 2003;63(2):131-137. doi:10.1016/S0031-9422(02)00657-X.

20. Neto MM, da Costa JA, Garcia-Cairasco N, Netto JC, Nakagawa B, Dantas M. Intoxication by star fruit (Averrhoa carambola) in 32 uraemic patients: treatment and outcome. Nephrol Dial Transplant.
2003;18(1):120-125. doi:10.1093/ndt/18.1.120.

21. Chen LL, Fang JT, Lin JL. Chronic renal disease patients with severe star fruit poisoning: hemoperfusion may be an effective alternative therapy. Clin Toxicol (Phila). 2005;43(3):197-199. doi:10.1081/ CLT-57872.

22. Martin LC, Caramori JST, Barreti P, Soares A. Intractable hiccups induced by carambola (Averrhoa carambola) ingestion in patients with end-stage renal failure. J Bras Nefrol. 1993;15:92-94.

23. Tsai MH, Chang WN, Lui CC, et al. Status epilepticus induced by star fruit intoxication in patients with chronic renal disease. Seizure. 2005;14(7):521-525. doi:10.1016/j.seizure.2005.08.004.

24. Chen $\mathrm{CL}$, Fang $\mathrm{HC}$, Chou KJ, Wang JS, Chung HM. Acute oxalate nephropathy after ingestion of star fruit. Am J Kidney Dis. 2001;37(2):418-422. doi:10.1053/ajkd.2001.21333.

25. Garcia-Cairasco N, Moyses-Neto M, Del Vecchio F, et al. Elucidating the neurotoxicity of the star fruit. Angew Chem Int Ed Engl. 2013;52(49):13067-13070. doi:10.1002/anie.201305382.

26. Wang CS, Wei YP, Swi Bea Wu J. Reduction of oxalic acid content in sour carambola juice by evaporation concentration and precipitate removal. Food Sci Taiwan. 1998;25:490-496. 